\title{
Creating Pioneers for an Unknown Land: Education for the Future
}

Copyright (C) 1998, Stephanie Pace Marshall

In a recent Chicago Tribune interview with Mary Catherine Bateson, anthropologist, author and daughter of Margaret Mead and Gregory Bateson, Ms. Bateson was asked, "How does a parent today prepare a child for a future world that is difficult for that parent to imagine?"

Bateson replied, "Suppose you knew that your child would be part of a group that went to form the first colony on another planet, how would you prepare this child for life there? That's the kind of thing we should be asking ourselves about education. You can't prepare the child for the job market that will exist 20 years from now. So how can you build a curriculum that will shape an individual to be a pioneer in an unknown land - because that's what the future is..." (Bateson, 1998).

Reflective educators long have asked this question, but never has the need for a response grounded in new insights about human learning and the transformation of the traditional schooling structures been more essential. The quality of our future is extricabably connected to our capacity to learn continuously; this capacity will be the new measure of "wealth" and "wealth creation" in the knowledge era.

\section{The Educational Contract}

Because continuous learning and knowledge generation are the core competencies in our ability to resolve the problems facing us as a world community, we must embrace the emerging new paradigm of learning. Schools, teachers, students and communities must change to develop the creative, adaptive, and purposeful learners required in the next millennium.

The educational "contract" for the $19^{\text {th }}$ Century school was based on an efficiency model that prescribed our current structures of teaching, learning and schooling. This model encouraged us to accept false proxies like seat time and coverage as legitimate indicators of genuine understanding.

As a result, we created "brain antagonistic" learning environments that actually inhibit integrated thought; distort the learner's identity and competence; make pattern formulation and constructed meaning difficult; and discourage skepticism, inventiveness, inquiry and complex cognition - the very skills and predispositions needed for the knowledge era.

I believe the current "structures of schooling" are (self-contained classrooms, didactic instruction, uniform progression, prescribed knowledge, and assessment based on course accumulation), especially at the high school level, 
are on a collision course with what we are coming to understand about human learning and the conditions necessary for exceptional learning by all students.

Learner-as-pioneer is an apt metaphor for an unpredictable and highly complex world. It requires that learners acquire the knowledge and skills essential for exploring and navigating this unknown land. What kind of learning environment would enable them to do so? Fortunately, we have some new tools.

Revolutionary new knowledge about the natural world, human learning, and even the brain/mind itself are converging to provide powerful insights. Over time these will enable us to transform the current structures and processes of schooling and create robust, reliant and sustainable learning environments that empower learners and engage their full capacity.

\section{Why is transformation necessary?}

For more than a decade, educators in the United States have been barraged with reports and rhetoric contending there is a crisis in public education. I believe the crisis is really about learning and the structures we have designed to support it.

We are recognizing and reframing the problem now because new discoveries in fields as diverse as quantum physics, chaos mathematics, evolutionary biology, systems theory, and the neuro and cognitive sciences, as well as advances in imaging technology such as CAT scans, functional MRIs, and PET scans (that enable us to observe a brain learning) are causing us to undertake two fundamental shifts in thinking:

1. The shift in world view from a machine-based "clockwork" conception of the world (a world of independent parts) to a complex adaptive and reflective system perspective (a world of interdependent relationships).

2. The shift from understanding the brain as a serial computer to be programmed and learning as a process of information accumulation and consumption, to understanding the brain as a "holistic," self-adjusting, interactive, neural network and learning as a natural, active and messy process of pattern formulation and constructed meaning.

Inherent in these "old" mental models are three mechanistic metaphors that historically have framed our view of schooling and learning: universe as clock, brain as computer and learner as tabula rasa.

Because we are captives of the images we hold and because language and image create context, these metaphors and the beliefs and assumptions that ground them conditioned us to create the schooling and learning structures we now have. But the discoveries and insights emerging from the cognitive sciences 
(and cautiously from the neurosciences) have altered these metaphors fundamentally and in so doing have radically reframed our understanding of and discourse on schooling. In place of the machine-based metaphors we now have organic and biological constructs that put current schooling structures in dynamic opposition to this new knowledge.

Because behavior is a consequence of thinking, we must ask ourselves why so many schools are perceived by learners as "antiseptically rational;" why so many classroom environments seem to discourage the emotional and spiritful dimensions of who we are; and why so many young people feel that schooling must be endured as a necessary rite of passage unrelated to life.

My response to these questions is straightforward: By accepting and internalizing a predictive and closed system world view and by accepting and internalizing a view of the brain as a serial computer to be programmed, we accepted a predictive and algorithmic view of learning and schooling based on the following assumptions:

1. Learning is an externally directed, passive and serial process of acquiring information -- not a self-directed, internally-mediated, dynamic and complex process of discovering and constructing meaning through pattern formulation.

2. Intelligence is a fixed capacity and is not learnable; analytical intelligence is the "highest form" of intelligence.

3. Emphasizing authentic learning tasks that are complex, challenging, and novel interferes with content and information acquisition.

4. Emotions, beliefs and "personal realities" constructed from prior experience do not influence and are not relevant to serious learning.

5. Learning is defined by the calendar (seat time, courses taken) and not demonstrations of authentic understanding; these "false proxies" are "legitimate" indicators of learning.

6. Content coverage and reproduction are more reliable indicators of learning than genuine understanding; content segmentation is more highly valued than concept integration.

7. Rote memory is better than spatial memory.

8. Prior knowledge is unimportant to future learning; the mind does not work to connect information in holistic ways. 
9. Reliable evaluation can only be objective and external, not qualitative and self-correcting and not conducted within settings that are real world (because they are messy, distracting and take us off course).

10. Competition and external rewards are more powerful motivators than collaboration, intrinsic motivation, and the pursuit of personalized and meaningful goals.

11. The didactic approach to instruction serves most learners equally well; learning conditions do not need to adapt to the multiple intelligences of learners.

12. The primary conditions of thoughtfulness Rex Brown describes (including mystery, uncertainty, disagreement, important questions and ambiguity are thought to be soft and lacking in rigor (1991, p. 234).

These learning "design principles" enabled us to create the perfect structure for dispensing and acquiring information. In doing so, however, we severed the connection between learning and life and created environments that suppressed reflective thought, creativity, and the innate capacity and desire we have for lifelong growth.

\section{Designing New Environments}

If we want to develop powerful, self-directed, inquiring, collaborative, and courageous pioneers, we must create learning conditions based on new design principles - principles derived from our emerging understandings of cognition (mind) and neuroscience (brain).

The last decade has produced remarkable new insights about human learning and how we can design environments that accelerate our natural learning processes.

There is a caveat, however, to our desire to "apply" brain science (neuroscience) to the transformation of schooling structures, and few better clarify this tension than John T. Bruer. In his article "Education and the Brain: A Bridge Too Far," Bruer (1997) provides a useful distinction between neuroscience (brain science) and cognitive science (mind science). He says that despite the fact that neuroscience is fascinating to educators, at this point it "has little to offer" in terms of how to structure learning environments. Due to premature applications of neuroscience to education, misconceptions and over generalizations have proliferated.

While Bruer maintains that the bridge between neuroscience and education may be "a bridge too far," he believes that the science of mind "can serve as a basic science for the development of an applied science of learning 
and instruction" and contends that, in time, advances in neuroscience may provide useful and important insights about teaching and learning. For now, however, the important connection for educators is the "bridge" between neuroscience and cognitive psychology.

\begin{abstract}
Currently, we do not know enough about brain development and neural function to link that understanding directly, in any meaningful, defensible way to instruction and education practice. We may never know enough to be able to do that. The positive conclusion us that there are two shorter bridges, already in place, that indirectly link brain functions with educational practice. There is a well-established bridge, now nearly 50 years old, between education and cognitive psychology. There is a second bridge, only around 10 years old, between cognitive psychology and neuroscience. This newer bridge is allowing us to see how mental functions map onto brain structures. When neuroscience does begin to provide useful insights for educators about instruction and educational practice, those insights will be the result of extensive traffic over this second bridge. Cognitive psychology provides the only firm ground we have to anchor these bridges. It is the only way to go if we eventually want to move between education and the brain (Bruer, 1997, p. 4).
\end{abstract}

Although current knowledge about the structural development and neural functioning of our brain is insufficient to use it in to create learning conditions, there does seem to be an emerging set of brain/mind principles that can inform our thinking. Formulated by Renate and Geoffrey Caine, these "serve as prisms for integrating research in many fields and guiding the ways in which we think about the brain..." [and]...serve to bring to educators at least 12 coherent factors that reliably and with integrity describe learning..." (1998).

\title{
What Are the Brain/Mind Principles?
}

1. The mind/brain is a complex adaptive system; thoughts, emotions, imagination, and predispositions operate concurrently.

2. Learning engages the entire physiology; there is a direct relationship between our physiological functioning and our capacity to learn.

3. The search for meaning is innate; the brain resists having meaninglessness imposed on it.

4. The search for meaning occurs through "patterning;" learners construct meaning through creating patterns of connections.

5. Emotions are critical to patterning; emotions and thoughts shape each other and cannot be separated.

6. Every mind/brain simultaneously perceives and creates parts and wholes; in a healthy person, both hemispheres interact in every activity. 
7. Learning involves both focused attention and peripheral perception; the brain absorbs information of which it is directly aware, but it also directly absorbs information that lies beyond the immediate focus of attention.

8. Learning always involves conscious and unconscious processes; because entire experiences are processed, understanding may occur well after information was experienced.

9. The mind/brain organizes memory in at least two different ways (spatial memory system and a set of systems for rote memory).

10. Learning is development. Development occurs in several ways. In part the brain is "plastic;" much of its "hard wiring" is shaped by experience.

11. Learning is enhanced by challenge and inhibited by threat. The brain learns it makes maximum connections optimally when appropriately challenged, but "downshifts" under perceived threat.

12. Every mind/brain is unique; there are different learning styles, talents and types of intelligences.

These brain/mind principles provide an increasingly compelling set of constructs to inform the creation of learning environments that liberate the genius and goodness of all children and invite the creativity and imagination of the human spirit.

These environments will enable learners to:

- Direct their own learning toward greater coherence, complexity, and rigor

- Increase their intellectual, social and emotional engagement with and responsibility to others

- Foster collaborative approaches to learning to enable them to develop integrative ways of knowing and understanding

Although an increasing number of high school students graduate with presumed disciplinary mastery, evidence suggests they also graduate with thinking characterized by stereotypes, misconceptions, unexamined assumptions, and rigidly held algorithms that do not enable them to achieve genuine understanding.

We must create a learning culture that provides a forum for risk, novel experimentation, and challenge and that gives power, time, and voice to student inquiry and creativity. 
Such a community, governed by the principles of natural learning and not the current structures of schooling, is characterized by:

- Personalization and coherence -- Questions that are significant to the human condition drive the curriculum, and knowledge is not separated into distinct and unconnected disciplines.

- Internal and external connections -- Because learning happens everywhere, student learning must transcend classroom and school boundaries.

- Richness in information, flexible and diverse learning experiences, and pathways for all learners -- Students are actively engaged in meaningful research and inquiry; they study "big" concepts and problems that are relevant to the real world.

- Intergenerational learning -- Margaret Mead said that the healthiest learning environment occurs when three generations learn together.

- Collaborative inquiry -- Students engage with adults and peers and draw upon the experiences of the whole group.

- Focus on complex cognition, problem-finding, and problem resolution.

Using the new brain/mind "design principles," we must create conditions for learning that foster the use and transference of multiple symbol systems (mathematics, science, art, music); encourage students to immerse themselves in authentic inquiry over extended periods of time; and enable students to integrate concepts, participate in the important work of the community, and become ethical stewards of their communities and the world's resources. Unless we do, I fear we will continue to develop youngsters who cannot understand the complexities and interconnections among different forms of knowledge, fear risk and experimentation, seek simple and narrow solutions to complex problems, and lack the intellectual fluency to become lifelong learners.

In 1991, Howard Gardner in his book The Unschooled Mind: How Children Think and How Schools Should Teach, proposed two of the best structures for learning: museums and apprenticeships. What is it about a museum that captures a young person's fantasy and imagination and engages her in genuine discovery? What is it about the apprenticeship relationship that enables one to safely acquire and practice new learning and skills?

My response is they actively engage learners in real-life experiences; they foster experimentation and collaborative inquiry; enable students to link their natural and more intuitive ways of learning with more formal and disciplinary forms of knowledge creation; and invite young people to reconnect learning and life. 
When a student can receive a 5 on an Advancement Placement test in physics and yet not understand some basic concepts in physics, something is wrong. When a student can graduate from Harvard and not understand why it is warmer in summer than winter (video made at Harvard called "The Private Universe"), something is wrong.

Somewhere there has been a profound disconnect between school-age education and lifelong learning; reconnecting them will require that we use knowledge from the cognitive and neurosciences to create conditions that will increase the learning capacity and power of every student. Until we do so, our student pioneers will not be able to navigate the unknown future that awaits them. $\sim \boldsymbol{B}$

\section{References}

Bateson, C. "On the Record"; an interview in the Chicago Tribune, February 1, 1998.

Bruer, John T. "Education and the Brain: A Bridge Too Far, Educational Researcher, November, 1997, pp. 4-16.

Caine, R. and Caine, G. "Making Connections: What Brain Research Tells us about Learning", Wingspread Journal, Vol. 18, Issue 3, Summer 1996, pp. 9-11.

"How to think about the Brain", School Administrator, American Association of School Administrators, January 1998, pp.1-7.

Gardner, H. The Unschooled Mind: How Children Think and How Schools Should Teach, New York: Basic Books, 1991.

Stephanie Pace Marshall is the founding President of the Illinois Mathematics and Science Academy in Aurora, Illinois. 